\title{
Applying the Lean principles of the Toyota Production System to reduce wait times in the emergency department
}

\author{
David Ng, MD; Gord Vail, MD, MSc; SophiaThomas, MD; Nicki Schmidt, RN
}

\section{ABSTRACT}

Objective: In recognition of patient wait times, and deteriorating patient and staff satisfaction, we set out to improve these measures in our emergency department (ED) without adding any new funding or beds.

Methods: In 2005 all staff in the ED at Hôtel-Dieu Grace Hospital began a transformation, employing Toyota Lean manufacturing principles to improve ED wait times and quality of care. Lean techniques such as value-stream mapping, just-in-time delivery techniques, workplace organization, reduction of systemic wastes, use of the worker as the source of quality improvement and ongoing refinement of our process steps formed the basis of our project.

Results: Our ED has achieved major improvements in departmental flow without adding any additional ED or inpatient beds. The mean registration to physician time has decreased from 111 minutes to 78 minutes. The number of patients who left without being seen has decreased from $7.1 \%$ to $4.3 \%$. The length of stay (LOS) for discharged patients has decreased from a mean of 3.6 to 2.8 hours, with the largest decrease seen in our patients triaged at levels 4 or 5 using the Canadian Emergency Department Triage and Acuity Scale. We noted an improvement in ED patient satisfaction scores following the implementation of Lean principles.

Conclusion: Lean manufacturing principles can improve the flow of patients through the ED, resulting in greater patient satisfaction along with reduced time spent by the patient in the ED.

Keywords: ED administration, Lean principles, length of stay, time to physician, wait time

\section{RÉSUMÉ}

Objectif : Compte tenu de la longueur des temps d'attente des patients et de la détérioration du niveau de satisfaction des patients et du personnel, nous avons cherché à améliorer ces mesures dans notre service d'urgence sans financement ou lits additionnels.
Méthodes : En 2005, l'ensemble du personnel du service d'urgence de l'hôpital Hôtel-Dieu Grace a amorcé une transformation, en appliquant les principes de production " au plus juste " de Toyota pour améliorer les temps d'attente et la qualité des soins. La base de notre projet était fondée sur les techniques au plus juste, comme la cartographie des flux de valeurs, la livraison juste-à-temps, l'organisation du milieu de travail, la réduction des gaspillages systémiques, le recours au travailleur en tant que source d'amélioration de la qualité et l'amélioration constante des étapes de nos processus.

Résultats : Notre service d'urgence a réalisé d'importantes améliorations en ce qui concerne le déroulement des activités sans avoir ajouté de lits supplémentaires à l'urgence ou dans I'hôpital. La moyenne de temps entre I'inscription et la consultation du médecin a diminué, passant de 111 à 78 minutes. Le nombre de patients quittant l'urgence sans avoir été vus par un médecin est passé de 7,1 à 4,3\%. La durée de séjour pour les patients qui ont obtenu leur congé a diminué, passant d'une moyenne de 3,6 heures à 2,8 heures. La plus forte baisse a été enregistrée chez les patients ayant un niveau de triage 4 ou 5 , selon l'échelle canadienne de triage et de gravité pour les services d'urgence. Nous avons observé une amélioration des scores de satisfaction des patients à l'urgence après l'application des principes de production au plus juste.

Conclusion : Les principes de production au plus juste peuvent améliorer le déplacement des patients à l'urgence, occasionnant une hausse de la satisfaction et une baisse de la durée de séjour des patients à l'urgence.

\section{INTRODUCTION}

Emergency department (ED) wait times have become a focus for the Canadian public, the media and the government. Factors external to the ED, such as improving access to inpatient beds, developing overcapacity protocols, adding clinical decision units and reorganizing

From the Emergency Department, Hôtel-Dieu Grace Hospital, Windsor, Ont.

Submitted Feb. 21, 2007; Revised Oct. 17, 2009; Accepted Oct. 20, 2009

This article has been peer reviewed. 
ambulance services have been proposed to improve ED patient flow. ${ }^{1,2}$ We have found few published reports that discuss improving internal ED efficiency to reduce wait times. Similar to most hospitals in Ontario, ED overcrowding and ambulance offload delay have been worsening at our site, due in part to a lack of available inpatient beds.,3 Our ED had previously attempted various solutions to improve wait times and attain recommended Canadian Emergency Department Triage and Acuity Scale (CTAS) wait time targets. Specifically, we increased the number of triage nurses and stations, added medical directives, increased physician staffing, hired a nurse practitioner and opened a fast track area. Despite these efforts there was little appreciable impact on overall ED wait times. In September 2005 our ED embarked on a makeover of our departmental processes, based on Lean manufacturing principles that were developed at the Toyota Motor Corporation. ${ }^{4}$

Lean techniques are widely used throughout the manufacturing industry to provide just-in-time delivery of product and ultimately to create value for the consumer using the least resources. These techniques have particular relevance to the current medical system in Canada, where the demand is outpacing capacity to provide care in a timely manner. Lean techniques have been adopted in some hospitals. ${ }^{5,6}$ The product manufactured in the ED can be considered timely, accurate and empathetic medical care. "Lean" is a term related to philosophies derived from the Toyota Production System. The main goals of the Lean system are to create standardized work in order to smooth out the workflow and to eliminate wasteful steps in a process. The Lean system concentrates on attaining continuous flow through a system by identifying value in each step of a process. If a step fails to add value or results in a redundancy to the next user in the process, it impedes quality and flow, and is eliminated (Box 1). By further reducing wait times between steps, and providing exactly what the next user in the process requires, quality and productivity improve. Lean thinking emphasizes identifying the root cause of a delay or problem by going to the worker and workplace to understand the demands of the work. Front-line workers are taught to identify waste, and to improve and standardize their step in the process.

Although many causes of ED overcrowding are a result of factors beyond the direct control of the ED, such as hospital inpatient capacity, there are factors within the scope of the department that could be changed to improve efficiency and patient satisfaction. The scope of our project involved improving the intradepartmental flow of patients discharged from a tertiary ED in Ontario. In our ED, approximately 85\% of patients are treated and discharged. By applying Lean techniques to the population of dischargeable patients, we hypothesized we would improve ED efficiency and productivity, and ultimately reduce ED wait times and improve patient satisfaction.

\section{METHODS}

\section{Setting and design}

We performed a before and after study. The ED of the Hôtel-Dieu Grace Hospital, in Windsor, Ont., is a regional trauma, cardiac, neurosciences, renal and psychiatric referral centre serving a population of 450000 . The annual census of the ED is approximately 55000 visits.

\section{Intervention}

The project began with a scoping exercise that was facilitated by a Lean consultant, Dr. John Long, to determine the parameters, participants and goals. Those participating were emergency physicians; nurses; nurse practitioners; porters; clerks; cleaning staff; administrators; the ED director, unit manager and educator; the hospital's senior vice-president; and representatives from diagnostic imaging, laboratory, respiratory therapy, home care and information services. All agreed that the focus would be CTAS- 2 to -5 patients deemed at initial triage to be "dischargeable," as opposed to

Box 1. The 7 sources of waste, with selected examples relevant to the emergency department

- Overproduction: creating more work than is required by the next step (e.g., over-triaging)

- Motion: extra steps for the worker or moving machinery around (e.g., "Where's the IV pole?")

- Waiting: time spent waiting for the next step in the process to occur (e.g., waiting for available bed, consultant, lab and diagnostic imaging results)

- Conveyance: moving materials around (e.g., lab results on paper)

- Processing: non-value added work steps (e.g., shuffling patients and stretchers to accommodate new arrivals)

- Inventory: excessive stockpiling of materials (e.g., 1000 tongue depressors in a drawer and no gel)

- Correction: reworking or scrapping work that has already been done (e.g., triage nurse reassessing patients in waiting room)

IV = intravenous. 
"admit" or "uncertain." We excluded patients presenting to the ED with primarily psychiatric complaints.

The group convened for a value-stream mapping kaizen workshop over 3 consecutive days in September 2005. The first day focused on creating a current-state map for dischargeable patients. The second day devised the future-state map of the ideal ED process. The last day outlined the improvement projects that would lead toward this ideal.

The current-state value-stream mapping exercise (Appendix 1, available at www.cjem-online.ca/v12/n1 /p50) created a view of the actual process steps involved in patient care for dischargeable patients. As a group, we placed each sequential step of work, from registration to postdischarge, on the current-state map. For each process step, we identified the suppliers (i.e., those who supply the work) and customers (i.e., those who receive the work). For each step, we estimated based on experience the process time, the prestep queue time (i.e., the wait time) and the frequency for which that step was both complete and accurate. We also mapped information flows, such as laboratory, diagnostic imaging and consultations. The group identified rework as occurring when process steps were repeated because of a change of information, or incomplete or inaccurate prior steps. We drew arrows on the map to connect the points of rework, forming rework loops. Once the current-state map was drawn out, it was possible to visualize the complexity of processing a patient through the ED. We summed the process times and wait times to determine the total lead time. At this point, with all the steps mapped out, we asked participants to identify 3 key bottlenecks in the entire value stream from registration to postdischarge. At the end of day 1, the group presented the current-state map and metrics to a decision panel, which included senior administrators and physicians within the hospital. The group answered questions, accepted criticisms and obtained approval to proceed to the future-state map.

Day 2 of the workshop involved the creation of the future-state value-stream map (Appendix 2, available at www.cjem-online.ca/v12/n1/p50). We reviewed the current-state map, and grouped sequential steps into components of care, creating "chunks." We either eliminated or combined repetitive process and work steps within each chunk. Between each chunk, we identified suppliers and customers, as well as inputs and outputs. To ensure the process steps within a chunk proceeded seamlessly, we established standard agreement on what inputs were required to begin each step, and what outputs were required at the end of each step. We identified the necessary changes required to meet the demands of the customer at each chunk as standard work. Finally, the group agreed on and set as the ideal target the expected length of time to complete each chunk (i.e., lead time). We then presented these results to the decision panel at the end of the day.

The final day of the workshop was the project planning phase. Projects were created around the "sort," "discharge" and "postdischarge" chunks of the futurestate map. We established 3 general priorities: workplace organization to improve the layout of the ED, creation of standard work that every worker was expected to do consistently and communication of Lean concepts and projects to the ED staff. We assigned project leaders, timelines, objectives and outcome measures to each project. We then presented the projects and implementation plans to the decision board for approval.

To illustrate, an initial key project involved sorting patients into admitted or dischargeable streams, based on the assumption that triage nurses could predict which patients would be discharged from the ED. Triage nurses were asked to assign the category of "discharge," "admit" or "uncertain" to each patient (Table 1). We excluded patients who arrived by ambulance, had primarily psychiatric complaints or were deemed CTAS-1 (emergent). We measured the accuracy of this decision during the day shift over 11 days. In March 2006, another project involved the reorganization of our ED into a probable admission area, a dischargeable area and a complex dischargeable area (i.e., for those uncertain patients requiring lengthier testing and care within the ED; e.g., renal colic, abdominal pain, atypical chest pain and asthma). All of these areas were located within our ED and represented, simply, a label attached to groups of existing beds.

To implement and sustain the projects, the ED leadership team created a Lean education and project board, organized staff information sessions, recruited front-line staff to be project team leaders and met weekly to review metrics. A full-group kaizen project

\begin{tabular}{|lccc|}
\hline \multicolumn{4}{|c|}{ Table 1. Accuracy of triage nurse to predict discharge } \\
\hline Prediction at triage & $\begin{array}{c}\text { Actually } \\
\text { discharged }\end{array}$ & $\begin{array}{c}\text { Actually } \\
\text { admitted }\end{array}$ & Total \\
\hline Predicted discharge & 650 & 22 & 672 \\
Uncertain & 87 & 23 & 110 \\
Predicted admission & 21 & 17 & 38 \\
Total & 758 & 62 & 820
\end{tabular}


review took place every 2 to 3 months. New projects were created based on staff suggestion and input, and were implemented on "suck-it-up Wednesdays." On this day new projects were trialed, and the ED staff was required to try the change and then provide feedback directly to team leaders, the Lean facilitator or the information graffiti boards.

\section{Outcome metrics}

Because of the lack of an electronic information system in our ED, all departmental metrics were manually compiled through the hospital health records department, and were posted on our communication board on a monthly basis. These metrics included the following:

- mean time to see a physician, defined as time from registration to documented time of physician encounter for all patients (i.e., door to doctor time)

- mean length of stay (LOS), defined as time of registration to the time that the patient physically left the department, for dischargeable patients

- mean LOS for all ED patients, including admitted patients

- proportion of patients who left without seeing a physician, defined as patients who left the ED before physician contact

- overall patient satisfaction score (based on the NRC Picker survey)

- overall ED volumes

- number of admitted inpatients in the ED at 6:00 am

\section{RESULTS}

We identified 19 process steps involving care of the dischargeable patient on the current-state value-stream map. The total process time ranged from 24 minutes to 19 hours, and the total wait time ranged from $37 \mathrm{~min}$ utes to 57 hours, for a total lead time of 61 minutes to 76 hours. When we multiplied the percentages of completeness and accuracy for each sequential step, we estimated only $2 \%$ of patients to have received flawless care through our system. Approximately $40 \%$ of patients had to repeat steps within the ED current-state value stream (total rework loops).

We organized the future-state map into 6 essential components or chunks. We estimated the total lead time on the future-state value-stream map to be 215 minutes, and we estimated this to be complete and accurate in $84 \%$ of cases.

The triage nurses correctly predicted which patients would be discharged with a sensitivity of $86 \%$ (true discharges/total discharges $=650 / 758)($ Table 1$)$. Approximately 1 in 7 patients $(110 / 820)$ was deemed "uncertain" at triage.

From April 2005 to September 2005, the mean wait time to see a physician was 111 minutes. The mean LOS for the discharged patient was 3.6 hours, and $7.1 \%$ of patients left the ED without being seen. Following the Lean workshop in September 2005, the mean wait time to see the physician decreased (Fig. 1). From October 2005 to March 2006, the mean wait time was 89 minutes. The mean LOS for discharged patients was 3.3 hours, and $5.0 \%$ of patients left without being seen. For the subsequent fiscal year between April 2006 and March 2007, the mean wait time to see a physician was 78 minutes. The mean LOS for discharged patients was 2.8 hours, and $4.3 \%$ of patients left without being seen (Fig. 2). The volume of patients seen in the ED remained stable throughout, but there was a substantial increase in ED crowding as measured by the boarding of admitted patients (Fig. 3). The mean number of admitted patients waiting for beds at 6:00 am daily was 1.3 in 2004, 1.8 in 2005, 4.1 in 2006 and 6.1 between January and March 2007.

The reductions in mean LOS were largely confined to patients triaged as CTAS-4 or -5. From April 2004 to March 2005, the mean LOS for CTAS-1, -2 and -3 patients was 4.7 hours; for CTAS-4 and -5 patients, the mean LOS was 3.1 hours. From April 2005 to March 2006, the mean LOS for CTAS-1, -2 and -3 patients

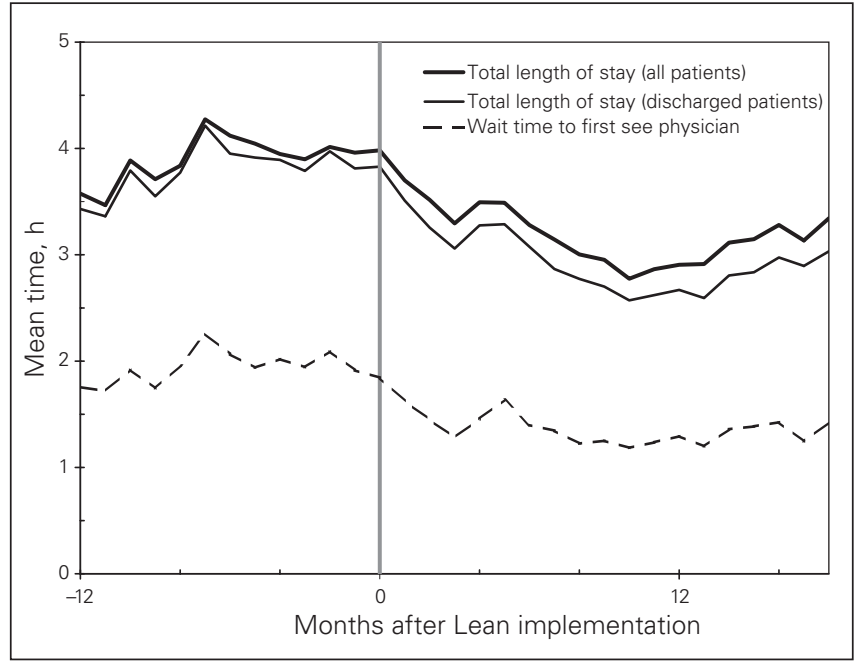

Fig. 1. Emergency department wait time and length of stay before and after intervention. Mean wait time (from registration to physician encounter) and length of stay (from registration to exiting department) for discharged patients and for all patients are displayed on a month-by-month basis. 
was 5.0 hours; for CTAS-4 and -5 patients, the mean LOS was 3.0 hours. From April 2006 to March 2007, the mean LOS for CTAS-1, -2 and -3 patients was 4.6 hours; for CTAS- 4 and -5 patients, the mean LOS was 2.3 hours.

Finally, patient satisfaction scores improved slightly and became more consistent after the intervention. From April 2004 to March 2005, the mean monthly score was $79.8 \%$, and met the provincial benchmark of $85 \%$ for 5 of the 12 months. From April 2005 to March 2006 , the overall annual mean was $82.0 \%$, and met the benchmark for 3 of the 12 months. From April 2006 to March 2007, the overall annual mean was $83.1 \%$ and met the benchmark for 6 of the 12 months (Table 2).

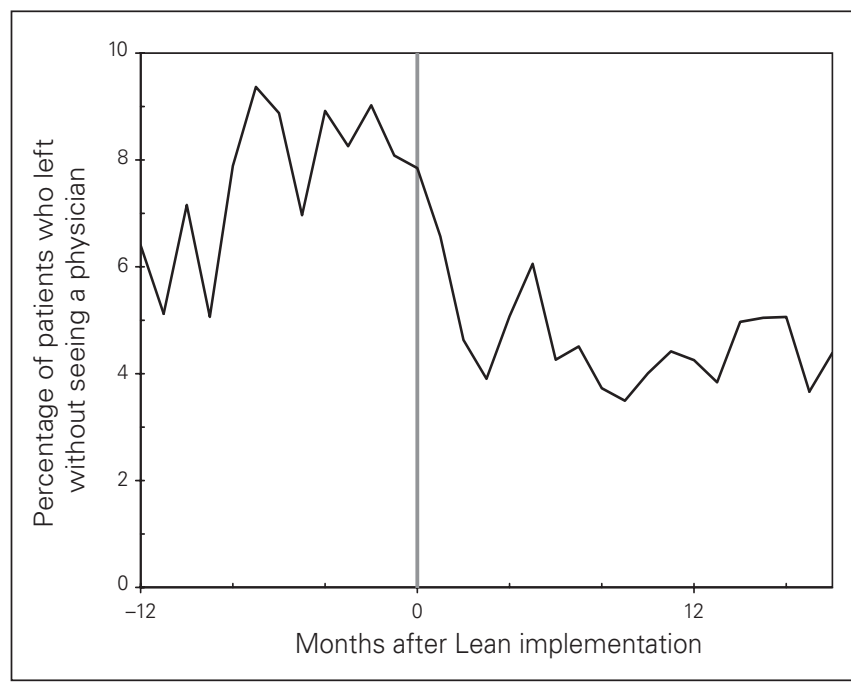

Fig. 2. Proportion of registered patients who left without being seen by a physician by month before and after intervention.

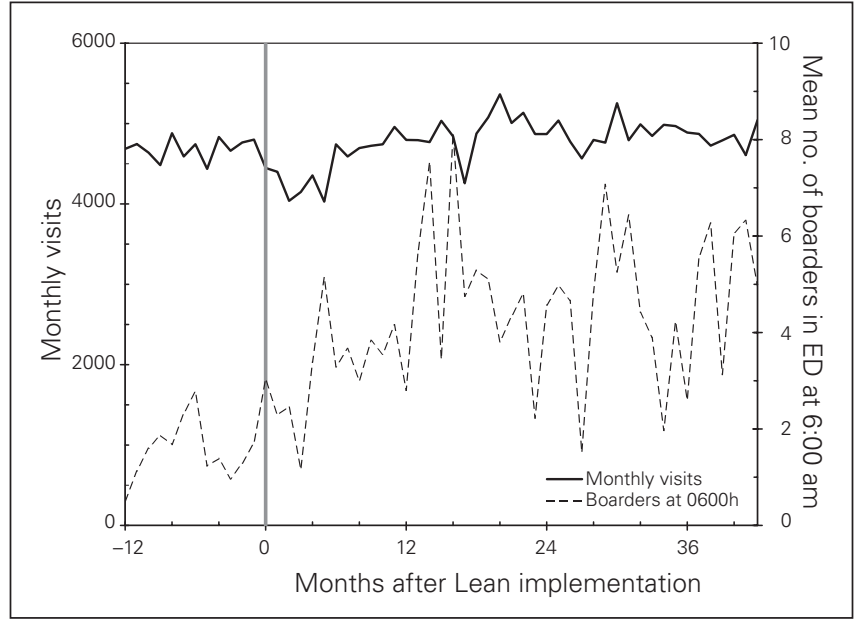

Fig. 3. Total visits (solid line) and mean number of inpatients held in the emergency department overnight (as counted at 6:00 am; dashed line) are shown on a month-by-month basis.

\section{DISCUSSION}

The causes of ED congestion are multifactorial, with hospital overcrowding and increasing ED demand as examples cited in the literature. ${ }^{2,3,8}$ Attempts to modify ED inputs, throughput and outputs to improve patient flow have been reported by others. ${ }^{1,8,9}$ We were able to find only a few published examples of applying industrial management techniques to improving hospital and ED flow, and these studies do not quantify sustained results. ${ }^{8,10,11}$ We report our experience in applying philosophies and tools from the Toyota Production System (Lean thinking) to improve productivity in our ED and to reduce wait times. For this project we focused on ED patients deemed by a triage nurse at presentation to be dischargeable. By reducing wasted steps and better coordinating the medical care for these patients, we hoped to improve the productivity of the ED. We prioritized organization of the workplace layout and standardization of the work, and established continuous communication of Lean concepts to the department.

While discussing and creating the value-stream maps, the group was able to see how inefficiently the ED operated. Previous efforts to improve access involved increasing ED processing at the point of triage. For example, medical directives for blood tests and full nursing assessments were implemented at triage because of an inability to bring patients into an overcrowded department. These directives often resulted in unnecessary or incomplete testing (Lean waste). Delays at triage were exacerbated by the need to reassess patients with extended waits in the waiting room (an example of rework). A single charge nurse was also responsible for responding to calls from the emergency

\begin{tabular}{|lccc|}
\hline \multicolumn{3}{|c|}{ Table 2. Overall patient satisfaction scores } \\
\hline \multicolumn{4}{c}{ Patient } \\
Month & $2004 / 05$ & $2005 / 06$ & $2006 / 07$ \\
\hline April & 65.0 & 78.8 & 73.7 \\
May & 85.0 & 83.3 & 86.4 \\
June & 92.3 & 79.6 & 83.7 \\
July & 83.9 & 91.7 & 85.1 \\
August & 87.0 & 79.6 & 79.3 \\
September & 74.2 & 75.0 & 78.2 \\
October & 89.7 & 72.0 & 88.5 \\
November & 80.8 & 83.3 & 86.5 \\
December & 73.7 & 80.6 & 85.1 \\
January & 75.9 & 87.5 & 87.5 \\
February & 64.5 & 84.2 & 80.4 \\
March & 85.7 & 89.1 & 83.3 \\
\hline
\end{tabular}


medical service, delivering printed laboratory results to the paper charts and escorting nonambulance patients into the ED. The lack of an ED information system and a central visual signal made it difficult to identify empty beds in the department. By directing patients to the next available bed, a nurse could be asked to care for patients of varying complexity, delaying the care of the patients requiring less intensive care. Nurses wasted time looking for equipment that was misplaced, in disrepair, inappropriately stocked or in the wrong location. Often-used materials such as intravenous (IV) solutions and opioids were stocked in central locations to ease the work for the hospital supply staff and pharmacy, but not for the main users of the material, namely the nurses. Porters escorted ambulatory patients to the diagnostic imaging department in batches, adding to patient wait times. There were no visual signals on the chart to indicate when investigations were complete. Physicians wasted time searching for charts, laboratory results and hospital records, causing unnecessary delay and frustration. On discharge, patients could linger in their beds for up to 45 minutes waiting for a nurse to deliver a prescription, to remove an IV lock, find a wheelchair or organize transport home. The entire flow of work within the ED was uneven, and lurched from those waiting for things to be done to those having too many tasks to do. The chaos precluded staff finding time to institute workplace improvements. The value-stream mapping exercise revealed much waste of effort and material in our ED.

The value stream exercise allowed a series of bottleneck reduction projects to be identified concurrently. Workplace organization projects had an immediate impact on efficiency. The front-line staff was asked to reconfigure these areas with the appropriate stock and ergonomics. Projects included stocking all physicianrequired material to the patient's right, reorganizing stock carts such that $90 \%$ of the most used stock were within steps of the patient, negotiating with stores and pharmacy to deliver stock to required areas in the required amounts, reducing stocking to maximum and minimum control levels (such as in a supermarket), footprinting or marking the ED floor with designated locations for necessary equipment to be placed after use (such as the previously wandering ECG machine). The entire department was reconfigured so that all dischargeable patients were seen in one area. All patients in the department were classified as "admitted," "uncertain" or "dischargeable" on presenting to the ED, and their charts would be placed in these respective boxes.
Incorrectly assigned patients could be reassigned at any time during their visit to the appropriate value streams. The nurses assigned to the dischargeable area were responsible for filling their own beds based on the visual cue of the charts in the inbox. This signal was akin to the Kanban box, which is used to signal work in a Toyota factory, allowing the worker to "pull" their work at a steady pace. Having a predictable workload created steady flow through the ED with an aim toward "just-in-time" delivery of care. Furthermore, a great emphasis was placed on reducing the time that a discharged patient stayed in a bed or chair. Nurses were encouraged to complete discharge procedures on patients before receiving the next patient or ambulance stretcher. Patients requiring home care were identified at triage and not on discharge. Physicians were encouraged to provide complete prescription and discharge instructions to the patient and pull IV locks in order to minimize delay of bed turnover. A discharged patient order box and a wheelchair availability project helped to reduce the time a discharged patient occupied an ED bed. Re-routing of laboratory results to the printer for the appropriate stream improved information flow. Ambulatory patients were encouraged to self-porter to diagnostic imaging, thereby freeing up porters for other work.

Improving efficiency for the dischargeable stream had a positive benefit for the rest of the ED. By increasing the throughput of patients through a limited but preallocated number of ED beds, remaining beds were freed for ambulance offload and boarding admitted patients. Physicians were also able to attend to higher acuity patients sooner. Workplace organization projects, such as streamlining stockrooms and standardizing IV carts had universal benefit in the ED. Placing dischargeable patients in a geographically distinct area of the ED opened other beds in the department for higher acuity patients likely to need admission. Furthermore, the improvement in ED patient turnaround time dramatically reduced the number of patients who left without being seen. Finally, as a result of improving ED process and wait times, there has been steady and progressive improvement in our NRC Picker scores for overall patient satisfaction since September 2005.

A major paradigm shift was required to think of patient flow in terms of work involved rather than diagnosis. By standardizing work based on worker consensus, medical error and miscommunication could be reduced while increasing the acceptance and sustainability of the change. The challenge of the Lean system is to train the workers to identify waste and to think in 
terms of the overall system and not just their own workstep. Each step in a process has a potential impact down the line, and what may be convenient for one worker may cause great inefficiency for the rest of the process. For example, physicians hoarding charts can reduce their distance walked, but impede the nurses' efficiency, which can result in overall delay for the patient.

The key to implementing the Lean system was the involvement of the front-line workers in creating plans and projects to improve their work, to run the projects as trials and to gather feedback to refine the project. This is known in Lean as a "Plan, Do, Check, Act" cycle. ${ }^{4,7}$ In the ED, a project would be implemented and trialed, feedback collected, and the project revised and reimplemented. Many projects, such as IV cart reorganization required repeated refinements, until the staff felt satisfied with their effectiveness. Other projects, such as the labelling of chart boxes to indicate what results were pending, were never embraced by staff despite repeated attempts.

By using the tools of value-stream mapping and Lean problem-solving, the ED also created side projects outside of the initial value-stream maps, such as reducing the turnaround time for blood availability in trauma and projects around our mental health and admitted patients in the ED.

Following the value-stream workshops in September 2005, and again following the separation of dischargeable stream patients in March 2006, there were distinct improvements in ED wait times.

The improvement in wait times at our ED has stabilized over the past year, and we continue to face new challenges. For example, the numbers of walk-in and ambulance arrivals, and admitted patients boarding in our ED continue to increase. The 2006 addition of a teaching unit in the hospital for internal medicine residents has added to the overcrowding and LOS for boarding patients admitted to the internal medicine service, because of a change in how patients are seen and admitted by the teaching service. The fact that our improvements in flow and satisfaction have occurred in the face of these overcrowding pressures is noteworthy.

The greatest challenge in implementing the Lean system involves creating and sustaining the ongoing projects, which requires leadership and support from ED and senior hospital management. There is cost to hiring a Lean consultant, developing in-house Lean expertise and paying for staff to participate in kaizen workshops. Individual projects are often done during clinical hours by front-line staff.
Increased ED efficiency also requires concomitant downstream improvement in information flow from laboratory, diagnostic imaging and physician consultation services. Hospital overcrowding is an issue beyond the scope of the ED and requires a more comprehensive hospital-wide strategy to improve patient flow. Based on the initial success of introducing the Lean system to our ED, our hospital has now created Lean projects in radiology, internal medicine, mental health and orthopedics.

\section{CONCLUSION}

We have applied Lean manufacturing techniques to improve the flow within our ED. We concentrated on the dischargeable patient group, which represents the majority of our patients. By eliminating waste from our internal ED processes, improving workplace organization, focusing on reducing interruptions and internal waits, and continuously refining improvements, wait times, length of stay and patient satisfaction have all improved during a period of increased ED overcrowding with no additional staff or beds. The Lean system provides an approach to analyzing process flow and improving efficiency by focusing on the ideas of frontline workers and providing maximum value to the customer. These principles represent a change in how we think about problems rather than a prescription for how to solve problems.

Acknowledgement: This paper is dedicated to our friend and sensei Dr. John Long (1943-2006).

Competing interests: None declared.

\section{REFERENCES}

1. Bond $\mathrm{K}$, Ospina MB, Blitz S, et al. Interventions to reduce overcrowding in emergency departments. Ottawa (ON): Canadian Agency for Drugs and Technologies in Health; 2006. Available: www.cadth.ca/media/pdf/320d_overcrowding_tr_e_no-appendices .pdf(accessed 2009 Nov 19).

2. Understanding emergency department wait times: How long do people spend in emergency departments in Ontario? Ottawa (ON): Canadian Institute for Health Information; 2007.

3. Hospital Emergency Department and Ambulance Effectiveness Working Group. Improving access to emergency services: a system commitment. Ottawa (ON): Ministry of Health and Long-Term Care; 2005. Available: www.health.gov.on.ca /english/public/pub/ministry_reports/emerg_dept_05/emerg _dept_05.pdf (accessed 2009 Nov 19). 
4. Liker JK. The Toyota way. Toronto (ON): McGraw Hill Books; 2004.

5. McCarthy M. Can car manufacturing techniques reform health care? Lancet 2006;367:290-1.

6. Terry Young, Brailsford S, Connell C, et al Using industrial processes to improve patient care. BMJ 2004;328:162-4.

7. Womack JP. Lean thinking. Banish waste and create wealth in your corporation. New York (NY): Free Press; 2003.

8. Committee on the future of Emergency Care in the United States Health System. Improving the efficiency of hospital based emergency care - bospital-based emergency care at the breaking point. Washington (DC): National Academy of Sciences; 2006.
9. Karpiel M. Improving emergency department flow. Eliminating ED inefficiencies reduces patient wait times. Healthc Exec 2004;19:40-1.

10. Lingaard Laursen M. Gertsen F, Johansen J. Applying lean thinking in hospitals - exploring implementation difficulties. Aalborg (Denmark): Aalborg University; 2003.

11. Schaming J, Gulati A. Health care quality improvement in the emergency department: a reengineering approach. Top Health Inf Manage 1998;18:70-80.

Correspondence to: Dr. David Ng, Emergency Department, Hôtel Dieu Grace Hospital, 1030 Ouellette Ave., Windsor ON N9A 1E1; dng@hdgh.org 
Current State Value Stream Map -ED Department

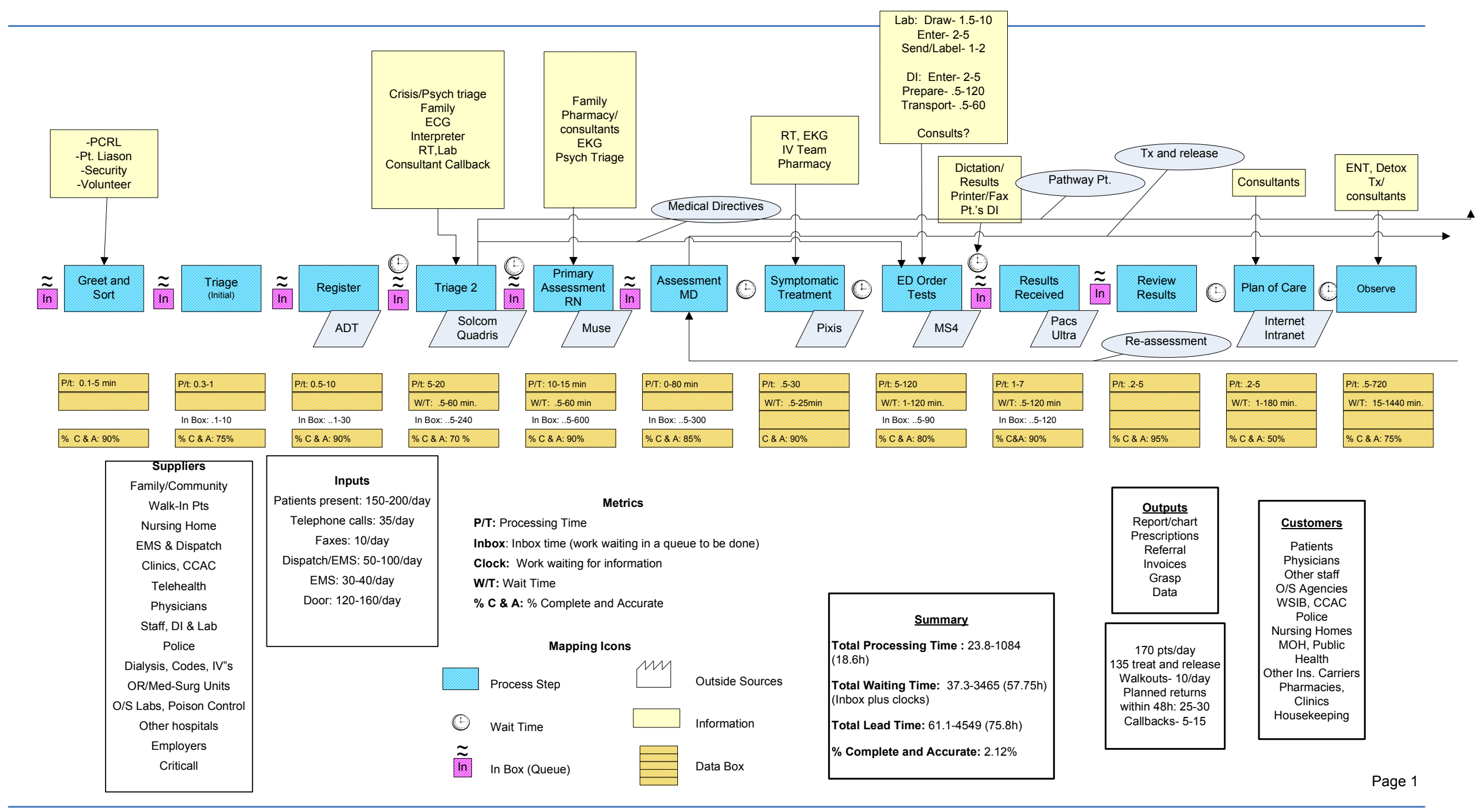




\section{Current State Value Stream Map- ED Department}

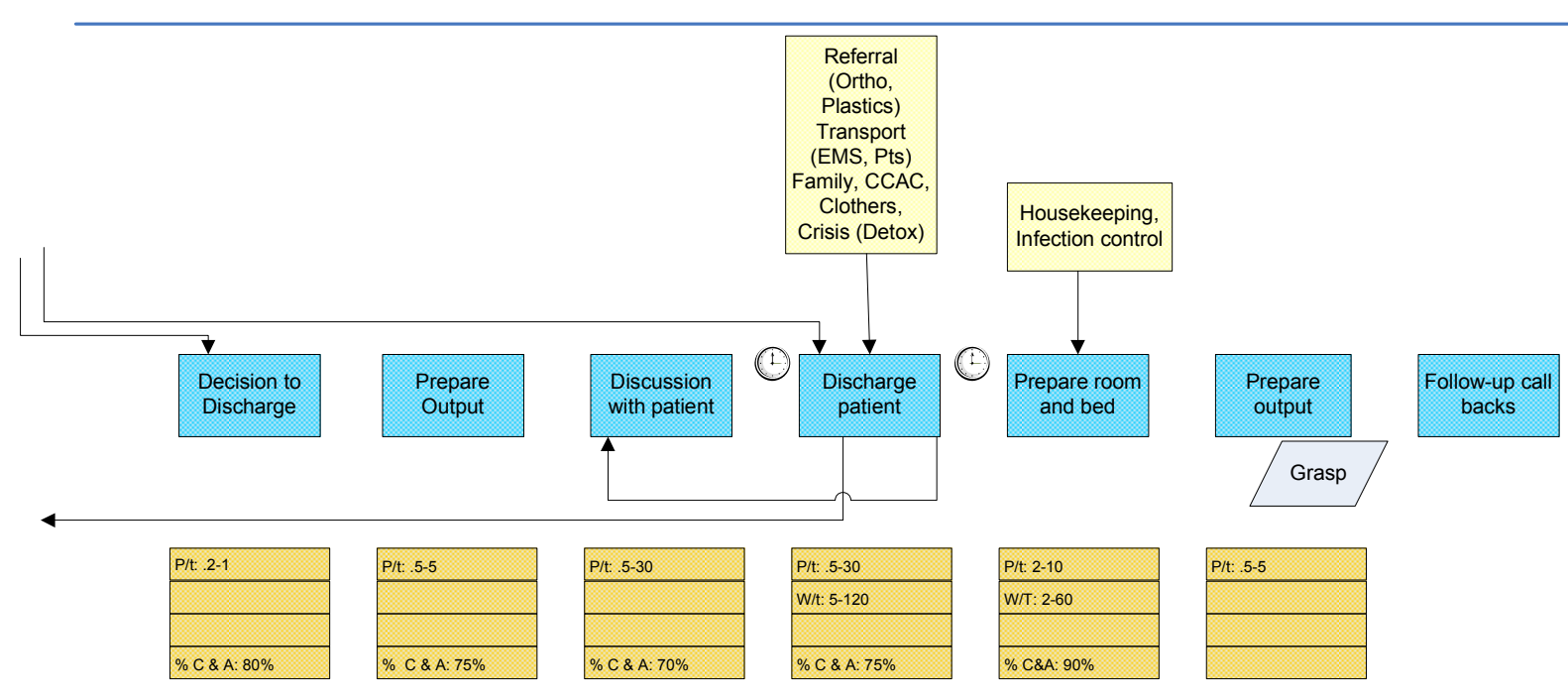

$$
\begin{aligned}
& \text { PIT: Processing Time } \\
& \text { Inbox: Inbox time } \\
& \text { W/T: Wait Time } \\
& \% \text { C \& A: \% Complete and Accurate } \\
& \text { Mapping Icons } \\
& \begin{array}{llll}
\square & \text { Process Step } & \text { Outside Sources } \\
\text { (1) Wait Time } & \square & \text { Information } \\
\tilde{\tilde{m}} & \text { In Box (Queue) } & \text { Data Box }
\end{array}
\end{aligned}
$$




\section{Future State Map- Emergency Department}

\section{CHUNK 1: Sort}

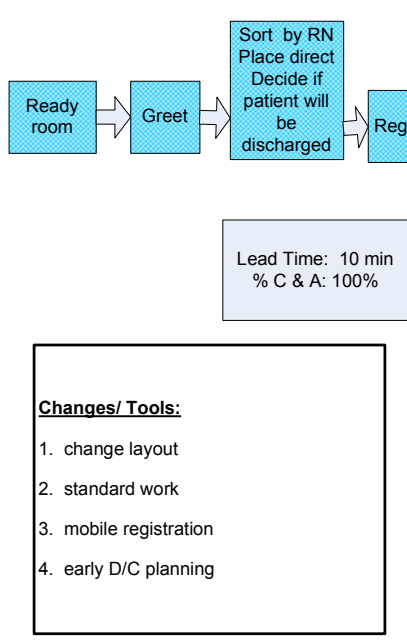

CHUNK 2: Assess and Order
Tests
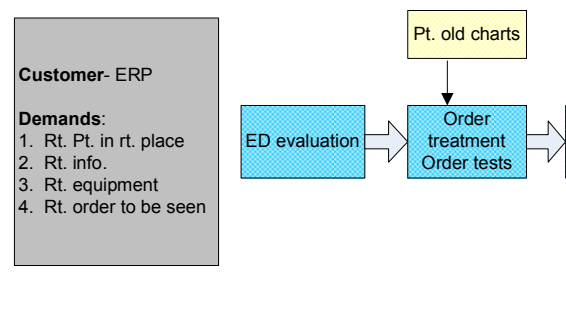

Start

treatment Draw blood

Lead Time: 30 min.
$\%$ C \& A: $95 \%$

Customer-Info

services

Demands:
1. No add-ons
3. $\&$ Anly

1. No add-ons
2. $\&$ A inputs
3. timely

3. timely

4. prepared pt.
5. clinical info.

\begin{tabular}{|l|}
\hline Changes/Tools: \\
1. Faster order entry \\
2. standard work \\
3. manage interruptions \\
4. Improve portering \\
\hline
\end{tabular}




\section{Future State Map- Emergency Department}

$$
\text { CHUNK 3: Decision }
$$

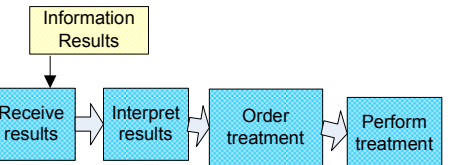

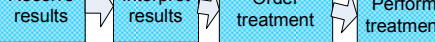

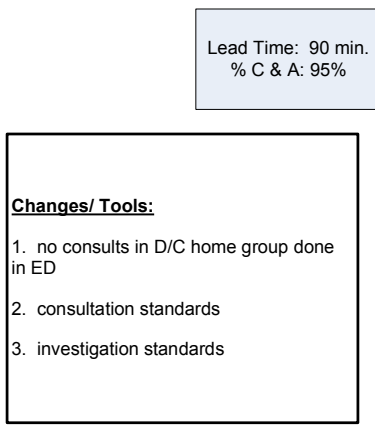

CHUNK 4: Discharge

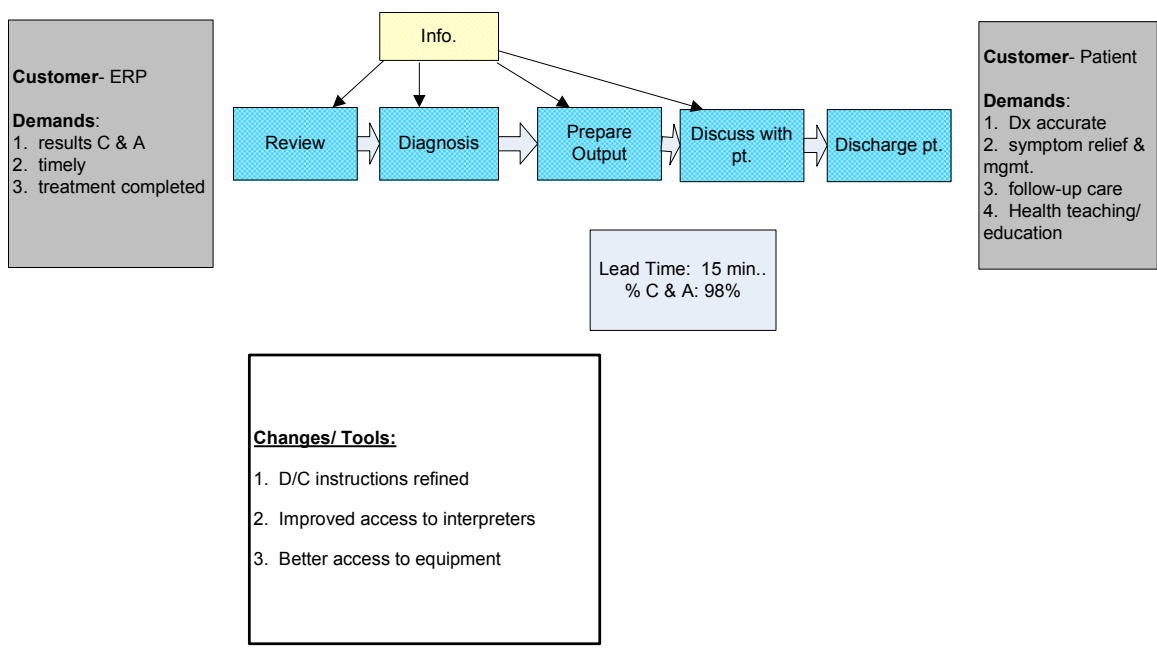




\section{Future State Map- Emergency Department}

CHUNK 5: Post Discharge

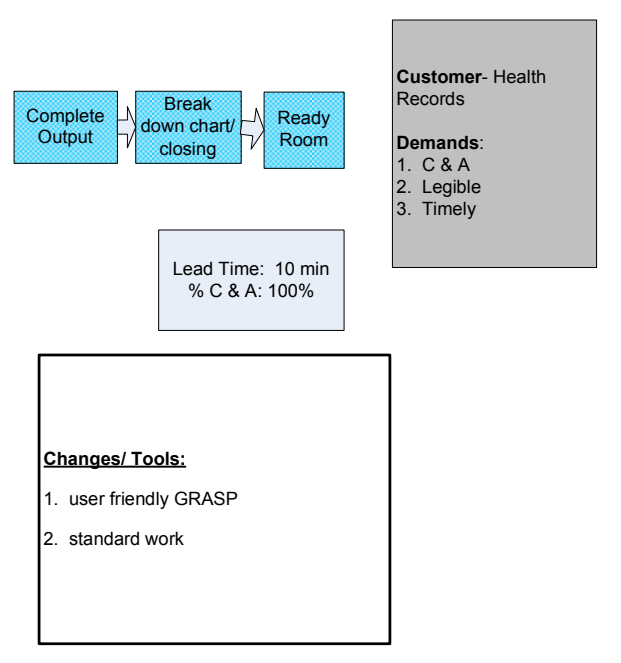

CHUNK 6: Call backs

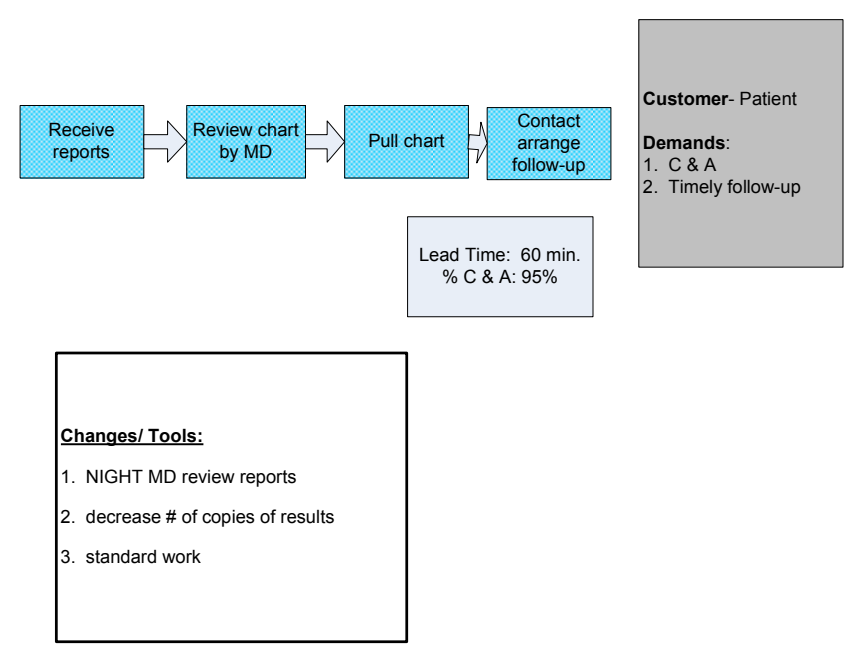

